\title{
The distribution of inherent phosphorus in fifteen water treatment residues from South Africa
}

\author{
M Norris and LW Titshall* \\ Soil Science, School of Agricultural, Environmental and Earth Sciences, University of KwaZulu-Natal, Private Bag X01, \\ Scottsville 3209, South Africa
}

\begin{abstract}
Water treatment residues (WTR), the by-products of the production of potable water, are chemically benign, inorganic materials which are suitable for disposal by land application, though they are frequently reported to have high phosphorus (P) sorption capacities. An understanding of the distribution of inherent P in WTR is, however, required, if sorption-desorption processes are to be correctly interpreted. The aim of this investigation was to characterise the chemical properties relevant to P-sorption/desorption processes of 15 South African WTR and to determine the inherent distribution of P within the WTR using a chemical fractionation procedure. The $\mathrm{pH}$, exchangeable $\mathrm{Ca}$ and organic carbon content ranged from 4.77 to 8.37 , 238 to $8980 \mathrm{mg} \cdot \mathrm{kg}^{-1}$ and 0.50 to $11.6 \mathrm{~g} \cdot 100 \mathrm{~g}^{-1}$, respectively. Dithionate, oxalate and pyrophosphate extractable $\mathrm{Al}$ fractions ranged from 741 to 96375,1980 to 82947 and 130 to $37200 \mathrm{mg} \cdot \mathrm{kg}^{-1}$, respectively, and dithionate, oxalate and pyrophosphate extractable Fe ranged from 441 to 15288,3865 to 140569 and 230 to $90000 \mathrm{mg} \cdot \mathrm{kg}^{-1}$, respectively. Mechanisms of P-retention are residue specific, being dependent on the chemical properties of the WTR. Elevated $\mathrm{Ca}$ and amorphous $\mathrm{Al}$ and Fe concentrations did, nevertheless, suggest that all residues had the capacity to adsorb high amounts of $\mathrm{P}$ and to retain this $\mathrm{P}$ in forms unavailable for plant uptake.
\end{abstract}

Keywords: Adsorption, chemi-sorbed, desorption, drinking water treatment sludge, land treatment

\section{Introduction}

The production of potable water from turbid primary sources requires the removal of suspended and dissolved solids, organic matter and other contaminants from the raw water source (Hughes et al., 2005). This is achieved through the addition of treatment chemicals which isolate unwanted constituents through flocculation and coagulation processes. The physical and chemical characteristics of the resulting water treatment residues (WTR) depend largely on the characteristics of the raw water source, the coagulant type used and dosage applied and other relevant facility-specific operating conditions (Babatunde and Zhao, 2007; Ippolito et al., 2011).

Water treatment residues have been classified as coagulant, lime or softening, natural or manganese residues, where coagulant and softening residues representing the majority of residues (approximately $70 \%$ and $25 \%$, respectively) (Babatunde and Zhao, 2007). Coagulant residues are formed when alum salts $\left(\mathrm{Al}_{2}\left(\mathrm{SO}_{4}\right)_{3} \cdot \mathrm{nH}_{2} \mathrm{O}\right)$, ferric salts $\left(\mathrm{FeCl}_{3}, \mathrm{Fe}_{2}\left(\mathrm{SO}_{4}\right)_{3}\right)$ and organic polymers are added to raw water (Ippolito et al., 2011). These materials act as effective coagulants by destabilising dispersed particles, providing new particles that accelerate the rate of particle collision and thus aggregation and by acting as strong adsorbents of dissolved organic materials and many trace contaminants (Elliott et al., 1990). Softening residues are comprised primarily of calcium and magnesium carbonates which are formed when lime, sodium hydroxide and/or soda ash are used to treat hard or alkaline water. Some water treatment

* To whom all correspondence should be addressed. Current address: Institute for Commercial Forestry Research, PO Box 100284, Scottsville, 3209

욜 +2733 386 2314; fax: +27 333868905 ; e-mail: Louis.titshall@icfr.ukzn.ac.za

Received 8 February 2012; accepted in revised form 18 September 2012. plants may also add organic polymers or metal salts to remove fine precipitates, colour or turbidity present in the raw water. In general, most WTR may be described as particulate or gelatinous substances composed of aluminium and iron hydroxides, carbonates of calcium and magnesium, inorganic particles such as clay or sand, coloured colloids, microorganisms and other organic and inorganic matter removed from the water being treated (Albrecht, 1972).

The chemical properties of WTR have been well documented, with many studies confirming their generally benign nature (e.g. Dayton and Basta, 2001; Ippolito et al., 2003; Titshall and Hughes, 2005; Babatunde and Zhao, 2007; Ippolito et al., 2011). Babatunde and Zhao (2007) and Ippolito et al. (2011) have reviewed research investigating the high phosphorus (P) sorption capacity reported for many WTR. The P adsorption and desorption behaviour of WTR has been linked to the presence of metallic hydrous-oxides, $\mathrm{Ca}$ and organic compounds, $\mathrm{pH}$, particle size and number of micro-pores (Dayton, 1995; Boisvert et al., 1997; Ippolito et al., 2003; Makris et al., 2005; Ippolito et al., 2011). Babatunde and Zhao (2010) investigated the kinetics of P-sorption of alum WTR. They report that initial sorption occurs on surface functional sites until these are saturated, and then by diffusion into pores for further sorption. They also found that the rate of sorption increased as the P concentration of the solutions increased. Yang et al. (2006) suggested that the sorption mechanism was through the displacement of surface functional groups by phosphate ions, indicating that ligand exchange processes were dominating.

It is due to the generally high P-sorption capacity of WTR that several studies have investigated the use of WTR to reduce $\mathrm{P}$ concentrations in P-contaminated environments (e.g. Dayton et al., 2003; Makris et al., 2005; Razali et al., 2007; Babatunde et al., 2008; Babatunde and Zhao, 2009). While a number of these studies have characterised the properties of WTR and related these to P-sorption capacity (see review by Ippolito et 


\begin{tabular}{|c|c|c|}
\hline \multicolumn{3}{|c|}{$\begin{array}{c}\text { Table } 1 \\
\text { The sequential fractionation procedure used to determine the distribution of inherent } P \text { within } 15 \text { South African } \\
\text { water treatment residues (adapted from Zhang and Mackenzie, 1997) }\end{array}$} \\
\hline P-fraction & Extractant & Procedure \\
\hline Soluble and loosely-held $\mathrm{P}_{\mathrm{i}}{ }^{\mathrm{a}}$ and $\mathrm{P}_{\mathrm{o}}^{\mathrm{b}}$ & $30 \mathrm{~m} \ell 1 \mathrm{~mol} \cdot \ell^{-1} \mathrm{NaHCO}_{3}$ & Shake for $16 \mathrm{~h}$, centrifuge at $4000 \mathrm{r} \cdot \mathrm{min}^{-1}$ for $10 \mathrm{~min}$ and filter \\
\hline $\begin{array}{l}\text { Aluminium and iron oxide surface- } \\
\text { bound } \mathrm{P}_{\mathrm{i}} \text { and } \mathrm{P}_{0}\end{array}$ & $30 \mathrm{~m} \ell 0.1 \mathrm{~mol} \cdot \ell^{-1} \mathrm{NaOH}$ & Shake for $16 \mathrm{~h}$ and centrifuge at $4000 \mathrm{r} \cdot \mathrm{min}^{-1}$ for $10 \mathrm{~min}$ and filter \\
\hline Calcium-bound $\mathrm{P}_{\mathrm{i}}$ & $30 \mathrm{~m} \ell 1 \mathrm{~mol} \cdot \ell^{-1} \mathrm{HCl}$ & Shake for $16 \mathrm{~h}$ and centrifuge at $4000 \mathrm{r} \cdot \mathrm{min}^{-1}$ for $10 \mathrm{~min}$ and filter \\
\hline Residual P & $\mathrm{H}_{2} \mathrm{SO}_{4}-\mathrm{H}_{2} \mathrm{O}_{2}$ digestion & $\begin{array}{l}\text { Add } 5 \mathrm{~m} \ell \text { conc. } \mathrm{H}_{2} \mathrm{SO}_{4} \text { and } 5 \mathrm{ml} \mathrm{H}_{2} \mathrm{O}_{2} \text { and digest at } 360^{\circ} \mathrm{C} \text { for } \\
3 \mathrm{~h} \text { and filter }\end{array}$ \\
\hline
\end{tabular}

a inorganically-bound $P$

${ }^{b}$ organically-bound $P$

al., 2011), no studies were found that investigated the chemical distribution of the inherent $\mathrm{P}$ in WTR. It is argued here that an understanding of the inherent (or natural) P content and distribution in WTR is required to better understand the sorptiondesorption behaviour and also the potential for land application or as an environmental P-sorbent. Thus the primary objective of this investigation was to characterise the inherent distribution of P within 15 South African WTR using a chemical fractionation procedure. This included separating the P in the WTR into labile (plant available) and non-labile (chemisorbed) fractions, with consideration of organically- and inorganically-bound phases. In addition, selected chemical properties that may affect the distribution of the inherent $P$ are investigated and the relationship between these properties, as well as the different $P$ fractions, determined using simple correlation statistics.

\section{Materials and methods}

\section{Material collection and chemical characterisation}

Fifteen WTR from a range of South African water treatment facilities were collected to represent a range of WTR types. With the exception of 1 WTR, all of the residues were generated through coagulation/flocculation processes, though information about specific treatment chemicals was not supplied by the water treatment facilities. In the case of the WTR 13, it was indicated that large amounts of lime were used resulting in a lime residue, though additional coagulation and flocculation were used for thickening purposes. The WTR were all air-dried and milled to pass a $2 \mathrm{~mm}$ sieve for chemical analysis, unless otherwise indicated. The $\mathrm{pH}$ was measured in distilled water using a Meter Lab PHM $210 \mathrm{pH}$ meter with a standard glass electrode in a WTR: solution ratio of 1:2 (10 g WTR:20 $\mathrm{m} \ell$ distilled water) after shaking for $1 \mathrm{~h}$ on a reciprocal shaker (Dayton, 1995). Exchangeable Ca was determined after extraction with $1 \mathrm{~mol} \cdot \ell^{-1} \mathrm{NH}_{4} \mathrm{NO}_{3}$ using a Varian Spectra AA200 atomic absorption spectrophotometer. Plant available phosphorus was estimated by extracting with AMBIC solution $(0.25$ mol $\cdot \ell^{-1}$ ammonium bicarbonate, $\mathrm{pH} 8.3$ ) and $\mathrm{P}$ was determined colourimetrically (The Non-Affiliated Soil Analysis Work Committee, 1990) on a Varian Cary 1E UV-Visible spectrophotometer. Readily oxidisable organic carbon (OC) was determined titrimetrically following potassium dichromate oxidation on $<0.5 \mathrm{~mm}$ material (Walkley, 1947).

Oxalate extractable $\mathrm{Al}, \mathrm{Fe}$ and $\mathrm{P}$ were determined after extraction with acid ammonium oxalate $(0.175 \mathrm{M})$ at $\mathrm{pH} 3$ (Loeppert and Inskeep, 1996). All residues were pre-treated with ammonium acetate to prevent the precipitation of Ca-oxalate salts. After extraction, samples were centrifuged at $3500 \mathrm{r} \cdot \mathrm{min}^{-1}$ for $10 \mathrm{~min}$ and analysed for $\mathrm{Al}, \mathrm{Fe}, \mathrm{Ca}$ and $\mathrm{P}$ using a Varian (720 ES) inductively coupled plasma-atomic emission spectroscope (ICP-AES). Phosphorus extracted during this procedure $\left(\mathrm{P}_{\mathrm{ox}}\right)$ was assumed to be bound to the amorphous $\mathrm{Al}$ $\left(\mathrm{Al}_{\mathrm{ox}}\right)$ and $\mathrm{Fe}\left(\mathrm{Fe}_{\mathrm{ox}}\right)$ component. The P-saturation index (PSI) for each residue was calculated as the molar ratio of $\mathrm{P}_{\text {ox }}$ to the sum of $\mathrm{Al}_{\text {ox }}$ and $\mathrm{Fe}_{\text {ox }}$ (Elliot et al., 2002; Dayton and Basta, 2005). A dithionate-citrate-bicarbonate extraction $(0.3 \mathrm{M}$ citrate, $1 \mathrm{~mol} \cdot \ell^{-1}$ bicarbonate and dithionate added in excess) (Mehra and Jackson, 1960) was used to determine the total amounts of free $\mathrm{Al}$ and $\mathrm{Fe}$ oxides. Extracts were analysed for $\mathrm{Al}$ and $\mathrm{Fe}$ by atomic adsorption spectroscopy (AAS) on a Varian Spectra AA-200. Organically-bound $\mathrm{Al}$ and $\mathrm{Fe}$ were determined after extraction with $0.1 \mathrm{~mol} \cdot \ell^{-1}$ sodium pyrophosphate (McKeague, 1967). Extracts were analysed for Al and Fe by AAS. All extractions, with the exception of the pyrophosphate extraction $(0.3 \mathrm{~g}$ samples), were carried out in duplicate on $0.5 \mathrm{~g}$ samples.

\section{Phosphorus fractionation}

The distribution of inherent $\mathrm{P}$ in the $15 \mathrm{WTR}$ was determined using a sequential phosphorus extraction procedure (Zhang and Mackenzie, 1997) on duplicate $0.5 \mathrm{~g}$ samples. This procedure identified soluble and 'loosely' held P (bicarbonate extraction), $\mathrm{Al}$ and $\mathrm{Fe}$ oxide surface bound $\mathrm{P}(\mathrm{NaOH}$ extraction), $\mathrm{Ca}$ bound $\mathrm{P}\left(\mathrm{HCl}\right.$ extraction) and residual $\mathrm{P}\left(\mathrm{H}_{2} \mathrm{SO}_{4}\right.$ digestion) (Table 1).

Aliquots of the bicarbonate and hydroxide extracts (10 to $15 \mathrm{~m} \ell$ ) were acidified with $2 \mathrm{~mol} \cdot \ell^{-1} \mathrm{HCl}$ to precipitate extracted organic matter and the supernatant analysed for inorganic $\mathrm{P}\left(\mathrm{P}_{\mathrm{i}}\right)$. The remainder of the bicarbonate and hydroxide extracts were analysed for total $\mathrm{P}$ after a $\mathrm{H}_{2} \mathrm{SO}_{4} / \mathrm{H}_{2} \mathrm{O}_{2}$ digestion (Zhang and Mackenzie, 1997). Organically bound $\mathrm{P}\left(\mathrm{P}_{\mathrm{o}}\right)$ was determined as the difference between total $\mathrm{P}$ and $\mathrm{P}_{\mathrm{i}}$. This permitted the separation of soluble and 'loosely' held $\mathrm{P}$ and $\mathrm{Al}$ and Fe oxide surfacebound $\mathrm{P}$ into their respective inorganic and organic components. Plant available $\mathrm{P}_{\mathrm{i}}$ was estimated by extracting with $1 \mathrm{~mol} \cdot \ell^{-1}$ bicarbonate and $0.1 \mathrm{~mol} \cdot \ell^{-1} \mathrm{NaOH}$. Inorganic $\mathrm{P}$ in all extracts and digestion solutions was determined colourimetrically by the molybdate blue method (Murphy and Riley, 1962). Total P was calculated as the sum of the fractionated components.

\section{Results and discussion}

\section{Chemical characteristics}

The range in $\mathrm{pH}$ values for the 15 WTR (4.77 to 8.37) (Table 2) was similar to that of 17 WTR from Oklahoma (5.29 to 7.77; Dayton, 1995). In most cases, the WTR were neutral to alkaline with the exception of the WTR 4 and 8 . Ammonium nitrate extractable calcium content ranged from $238 \mathrm{mg} \cdot \mathrm{kg}^{-1}$ in the acidic WTR 4 residue to $8980 \mathrm{mg} \cdot \mathrm{kg}^{-1}$ in WTR 5. The only 


\begin{tabular}{|c|c|c|c|c|c|c|c|c|c|c|c|c|}
\hline \multicolumn{13}{|c|}{$\begin{array}{c}\text { Table } 2 \\
\text { Selected chemical characteristics of } 15 \text { South African water treatment residues and the phosphorus sorption index }\end{array}$} \\
\hline \multirow[t]{3}{*}{ WTR } & \multirow[t]{3}{*}{$\mathrm{pH}$} & \multirow{3}{*}{$\begin{array}{l}O C^{a} \\
g \cdot 100 g^{-1}\end{array}$} & \multirow[t]{2}{*}{$\mathrm{Ca}$} & \multirow{2}{*}{$\begin{array}{l}\text { AMBIC }^{b} \\
P\end{array}$} & \multicolumn{2}{|c|}{ Dithionate } & \multicolumn{2}{|c|}{ Oxalate } & \multicolumn{2}{|c|}{ Pyrophosphate } & \multirow[t]{2}{*}{$P_{o x}{ }^{c}$} & \multirow{3}{*}{$\begin{array}{c}P_{\%} I^{d} \\
0\end{array}$} \\
\hline & & & & & Al & $\mathrm{Fe}$ & Al & $\mathrm{Fe}$ & Al & $\mathrm{Fe}$ & & \\
\hline & & & \multicolumn{9}{|c|}{$\mathrm{mg} \cdot \mathrm{kg}^{-1}$} & \\
\hline 1 & 7.04 & 9.13 & 1613 & 4.39 & 96375 & 2565 & 44727 & 6240 & 37200 & 11400 & 69.9 & 0.137 \\
\hline 2 & 7.56 & 2.07 & 3782 & 24.8 & 1171 & 700 & 2536 & 8980 & 310 & 840 & 71.3 & 0.619 \\
\hline 3 & 7.77 & 11.6 & 3080 & 7.10 & 78000 & 981 & 82947 & 75985 & 4070 & 1340 & 56.3 & 0.035 \\
\hline 4 & 5.92 & 9.93 & 238 & 3.04 & 19038 & 2978 & 36624 & 6178 & 24500 & 6400 & 22.8 & 0.053 \\
\hline 5 & 7.25 & 3.26 & 8980 & 34.9 & 741 & 5263 & 2822 & 53419 & 390 & 7470 & 30.5 & 0.054 \\
\hline 6 & 6.93 & 7.55 & 1080 & 6.42 & 17975 & 2059 & 33638 & 140569 & 9910 & 2500 & 18.3 & 0.011 \\
\hline 7 & 7.56 & 4.45 & 5577 & 4.62 & 12800 & 15288 & 4507 & 10341 & 5880 & 90000 & 57.2 & 0.385 \\
\hline 8 & 4.77 & 4.74 & 575 & 14.4 & 7063 & 1186 & 12615 & 9736 & 14850 & 7530 & 25.0 & 0.112 \\
\hline 9 & 7.29 & 3.85 & 3860 & 23.4 & 1583 & 2526 & 6260 & 5442 & 1150 & 1140 & 55.9 & 0.478 \\
\hline 10 & 7.82 & 2.56 & 2760 & 11.8 & 1228 & 1486 & 2953 & 18866 & 350 & 740 & 42.8 & 0.196 \\
\hline 11 & 7.44 & 0.50 & 2387 & 5.07 & 1139 & 1836 & 2546 & 21176 & 3470 & 3140 & 32.6 & 0.137 \\
\hline 12 & 7.54 & 1.27 & 3691 & 37.0 & 936 & 2524 & 2083 & 3865 & 270 & 4070 & 93.8 & 1.577 \\
\hline 13 & 8.37 & 0.72 & 1311 & 13.1 & 1283 & 441 & 3234 & 21342 & 130 & 230 & 31.8 & 0.129 \\
\hline 14 & 7.25 & 0.57 & 3433 & 1.01 & 1613 & 2134 & 1401 & 5338 & 1250 & 7410 & 19.4 & 0.288 \\
\hline 15 & 8.02 & 0.91 & 3747 & 2.59 & 1909 & 7113 & 1980 & 5952 & 200 & 1250 & 26.6 & 0.335 \\
\hline
\end{tabular}

a Ammonium bicarbonate $\mathrm{pH} 8.3$.

${ }^{b}$ Organic carbon.

${ }^{C}$ Oxalate extractable $P$

${ }^{d}$ Phosphorus Saturation Index $\left(P S I=\left[P_{o x}\right] /\left[A l_{o x}\right]+\left[\mathrm{Fe}_{0 x}\right]\right)$ where units were converted to molar ratios and presented as a percentage

lime residue (WTR 13) did not reflect the highest Ca content, suggesting that the form of $\mathrm{Ca}$ present in this residue was not in a readily available form. Titshall and Hughes (2005) had previously investigated WTR from the same water treatment facility and found that a relatively small proportion of the total Ca present in the WTR was readily available (approximately 2.5\%). However, in general, the range of these values suggests that there is varying potential for the formation of insoluble calcium phosphate compounds. Organic carbon content ranged between 0.50 and $11.6 \%$ (Table 2) and is related to the characteristics of the water treatment chemicals and raw water quality. The AMBIC extractable phosphorus values ranged from 1.01 to $37.0 \mathrm{mg} \cdot \mathrm{kg}^{-1}$, which likely reflects the variability in $\mathrm{P}$ concentrations of the raw water sources and treatment chemicals, though this was not specifically measured here. The highest AMBIC extractable P concentrations $\left(>20 \mathrm{mg} \cdot \mathrm{kg}^{-1}\right)$ were measured (in decreasing order) in the WTR $12>5>$ $2 \approx 9$ (Table 2). Typical AMBIC P concentrations for South African soils have been reported to range between 0.3 and $15.3 \mathrm{mg} \cdot \mathrm{kg}^{-1}$ (Schmidt et al., 2004), suggesting that the WTR with high $\mathrm{P}$ concentrations may be beneficial from an agronomic perspective and that the land application on P-deficient soils may be of some potential value.

Amorphous $\mathrm{Al}\left(\mathrm{Al}_{\mathrm{ox}}\right)$ and $\mathrm{Fe}\left(\mathrm{Fe}_{\mathrm{ox}}\right)$ ranged from 1401 to 82 $947 \mathrm{mg} \cdot \mathrm{kg}^{-1}$ for $\mathrm{Al}$ and 3865 to $140569 \mathrm{mg} \cdot \mathrm{kg}^{-1}$ for Fe (Table 2). The values reported here for $\mathrm{Al}_{\mathrm{ox}}$ are similar to those reported by Dayton and Basta (2005) for 18 WTR from Oklahoma (15 300 to $\left.84000 \mathrm{mg} \cdot \mathrm{kg}^{-1}\right)$, but $\mathrm{Fe}_{\text {ox }}$ values were generally higher in the WTR reported in this study than those of Dayton and Basta $\left(2005 ; 120\right.$ to $\left.12300 \mathrm{mg} \cdot \mathrm{kg}^{-1}\right)$. This may reflect differences in treatment chemical types and dosage as well as differences in the nature of the particulates removed from the raw water sources.

This non-crystalline component is of particular relevance with respect to P-sorption due to their large specific surface areas and chemical affinity for phosphate. The $\mathrm{P}$ saturation index (PSI) values show that for PSI $<100 \%$ there is an excess of reactive $\mathrm{Al}$ and $\mathrm{Fe}$ while $\mathrm{PSI}>100 \%$ indicates that reactive components are saturated by an excess of P (Elliot et al., 2002). The values measured ranged from 0.011 to $1.58 \%$, indicating a low P-saturation index (Table 2), suggesting that all the WTR investigated here have the potential to adsorb large quantities of P. Dayton and Basta (2005) reported PSI values that ranged from 0.25 to $6.34 \%$ for 18 Oklahoma WTR.

Dithionate extractable $\mathrm{Al}\left(\mathrm{Al}_{\mathrm{di}}\right)$ and $\mathrm{Fe}\left(\mathrm{Fe}_{\mathrm{di}}\right)$ varied from 741 to $96375 \mathrm{mg} \cdot \mathrm{kg}^{-1}$ for $\mathrm{Al}$ and from 441 to $15288 \mathrm{mg} \cdot \mathrm{kg}^{-1}$ for $\mathrm{Fe}$ (Table 2). This extraction, which removes finely-divided, crystalline mineral phases, amorphous inorganic $\mathrm{Al}$ and $\mathrm{Fe}$ and organic-complexed components, provides a measure of total 'free' Al and Fe oxide contents. Therefore, it was not expected that dithionate fractions would be, for the majority of residues, less than the poorly crystalline fractions removed with the oxalate extraction. Loeppert and Inskeep (1996) have noted that the dissolution efficiency of the dithionate reagent is strongly affected by particle size. Therefore, dithionate extraction efficiency may have been reduced due to insufficient reduction in particle size prior to analysis. However, the ease with which amorphous components are dissolved does suggest that particle size variation is of limited importance. Pyrophosphate extractable $\mathrm{Al}\left(\mathrm{Al}_{\mathrm{py}}\right)$ and $\mathrm{Fe}\left(\mathrm{Fe}_{\mathrm{py}}\right)$ values, which varied from 130 to $37200 \mathrm{mg} \cdot \mathrm{kg}^{-1}$ for $\mathrm{Al}$ and from 230 to $90000 \mathrm{mg} \cdot \mathrm{kg}^{-1}$ for $\mathrm{Fe}$ (Table 3), were generally less than oxalate and dithionate extractable fractions. Aluminium and $\mathrm{Fe}$ extracted in this procedure are considered organically bound and may consist of crystalline and amorphous fractions. Elevated values (e.g. WTR 1 and 7) may, therefore, reflect the additional dissolution of poorly ordered $\mathrm{Al}$ and Fe phases not associated with organic matter (Bertsch and Bloom, 1996). The positive correlation coefficient between oxalate and dithionate extractable Fe fractions (0.96; Table 3), in part, supports this argument. However, this relationship was not as clear for the oxalate and dithionate extractable Al fractions that had a markedly weaker correlation (0.53; Table 3$)$ than that of the Fe fractions. However, the positive correlation between $\mathrm{Al}_{\mathrm{ox}}$ and organic carbon content (0.56), while not a strong relationship, does suggest 


\begin{tabular}{|c|c|c|c|c|c|c|c|c|c|c|c|c|c|}
\hline \multicolumn{14}{|c|}{$\begin{array}{c}\text { Table } 3 \\
\text { Correlation table detailing the relations between WTR chemical properties and P fractions }\end{array}$} \\
\hline & $\mathrm{pH}$ & $\mathrm{Ca}$ & $\begin{array}{c}\text { Dith }^{a} \\
\text { Al }\end{array}$ & $\begin{array}{c}\text { Dith } \\
\text { Fe }\end{array}$ & $\begin{array}{c}\text { Ox }^{b} \\
\text { Al }\end{array}$ & $\begin{array}{l}\text { Ox } \\
\mathrm{Fe}\end{array}$ & $\begin{array}{c}\text { Pyr }{ }^{\mathrm{c}} \\
\text { Al }\end{array}$ & $\begin{array}{l}\text { Pyr } \\
\text { Fe }\end{array}$ & $\mathrm{OC}^{\mathrm{d}}$ & $\begin{array}{c}\text { Bicarbe } \\
\mathrm{Pi}\end{array}$ & $\underset{\mathrm{Pi}}{\mathrm{NaOH}}$ & $\mathrm{Po}^{\mathrm{f}}$ & $\mathrm{HCl} \mathrm{Pi}$ \\
\hline $\mathrm{Ca}$ & 0.38 & & & & & & & & & & & & \\
\hline Dithi Al & -0.04 & -0.23 & & & & & & & & & & & \\
\hline Dithi Fe & 0.13 & 0.5 & -0.09 & & & & & & & & & & \\
\hline Ox Al & -0.47 & -0.17 & 0.53 & 0.01 & & & & & & & & & \\
\hline $\mathrm{OxFe}$ & 0.15 & 0.65 & -0.13 & 0.96 & 0 & & & & & & & & \\
\hline Pyr Al & -0.55 & -0.49 & 0.68 & -0.04 & 0.88 & -0.13 & & & & & & & \\
\hline Pyr Fe & 0.01 & 0.31 & 0.03 & 0.89 & 0.02 & 0.84 & 0.08 & & & & & & \\
\hline $\mathrm{OC}$ & -0.37 & -0.3 & 0.78 & -0.04 & 0.56 & -0.05 & 0.67 & 0.06 & & & & & \\
\hline Bicarb Pi & 0.08 & 0.73 & -0.26 & 0.01 & 0.04 & 0.24 & -0.31 & -0.11 & -0.22 & & & & \\
\hline $\mathrm{NaOH} \mathrm{Pi}$ & 0.01 & 0.74 & -0.05 & 0.12 & 0.23 & 0.34 & -0.12 & -0.04 & 0 & 0.86 & & & \\
\hline Po & -0.14 & -0.53 & -0.05 & -0.17 & -0.15 & -0.31 & 0.13 & 0.09 & -0.11 & -0.44 & -0.7 & & \\
\hline $\mathrm{HCl} \mathrm{Pi}$ & 0.07 & 0.76 & -0.17 & 0.1 & 0.12 & 0.33 & -0.24 & -0.05 & -0.13 & 0.88 & 0.98 & -0.65 & \\
\hline P Resid". & 0.15 & 0.02 & 0.18 & 0.14 & 0.06 & 0.12 & 0.01 & -0.08 & 0.22 & -0.22 & 0.04 & -0.74 & -0.02 \\
\hline
\end{tabular}

a Dithionate extractable

${ }^{b}$ Oxalate extractable

c Pyrophosphate extractable

'Organic carbon

${ }^{e}$ Bicarbonate extractable

${ }^{f}$ Organic $P$ is calculated as the sum ofbBicarbonate $P_{o}$ and $\mathrm{NaOH} P_{o}$ fractions

g Residual $P$

\begin{tabular}{|c|c|c|c|c|c|c|c|c|c|c|c|c|c|}
\hline \multicolumn{14}{|c|}{ Fractionation of } \\
\hline \multirow[t]{3}{*}{ WTR } & \multicolumn{12}{|c|}{ Total P fractionated } & \multirow{4}{*}{$\begin{array}{c}\begin{array}{c}\mathbf{P}_{\text {Tot }}{ }^{b} \\
\mathbf{m g} \cdot \mathbf{k g}^{-1}\end{array} \\
1403\end{array}$} \\
\hline & \multicolumn{4}{|c|}{ Bicarbonate } & \multicolumn{4}{|c|}{$\mathrm{NaOH}$} & \multirow{2}{*}{\multicolumn{2}{|c|}{$\begin{array}{c}\mathrm{HCl} \\
\mathrm{P}_{\mathrm{i}}\end{array}$}} & \multirow{2}{*}{\multicolumn{2}{|c|}{$\begin{array}{c}\text { Residual } P \\
\left(P_{i}+P_{0}\right)\end{array}$}} & \\
\hline & \multicolumn{2}{|c|}{$P_{i}{ }^{a}$} & \multicolumn{2}{|c|}{$\mathbf{P}_{0}{ }^{a}$} & \multicolumn{2}{|c|}{$\mathbf{P}_{\mathrm{i}}$} & \multicolumn{2}{|c|}{$P_{0}$} & & & & & \\
\hline 1 & 0.33 & (4.63) & 21.6 & (303) & 0.96 & $(13.5)$ & 24.2 & (339) & 0.85 & (11.9) & 52.1 & (730) & \\
\hline 2 & 0.91 & (10.4) & 27.3 & (314) & 0.5 & $(5.79)$ & 27.4 & (315) & 1.91 & $(22.0)$ & 41.9 & (482) & 1149 \\
\hline 3 & 0.36 & $(5.23)$ & 18.5 & $(270)$ & 0.94 & (13.7) & 19.1 & (280) & 1.67 & $(24.5)$ & 59.4 & (870) & 1463 \\
\hline 4 & 0.33 & $(4.57)$ & 21.3 & $(295)$ & 0.35 & $(4.92)$ & 19.3 & (269) & 0.86 & $(12.0)$ & 57.8 & (803) & 1389 \\
\hline 5 & 1.78 & $(30.7)$ & 16.2 & $(281)$ & 7.17 & (124) & 8.42 & (146) & 12.1 & (209) & 54.3 & (938) & 1727 \\
\hline 6 & 0.33 & $(4.53)$ & 21.4 & $(295)$ & 0.6 & (8.24) & 22.5 & (310) & 0.81 & (11.1) & 54.3 & (746) & 1374 \\
\hline 7 & 0.34 & $(4.51)$ & 22.3 & $(297)$ & 0.41 & (5.44) & 24.2 & (322) & 1.13 & $(15.0)$ & 51.6 & (686) & 1329 \\
\hline 8 & 0.38 & $(4.89)$ & 25.1 & $(321)$ & 0.46 & $(5.86)$ & 25.2 & (323) & 0.84 & $(10.8)$ & 48 & (615) & 1280 \\
\hline 9 & 0.42 & $(5.90)$ & 18.1 & $(256)$ & 0.43 & $(6.09)$ & 22.9 & (324) & 1.13 & $(16.0)$ & 57.1 & (808) & 1416 \\
\hline 10 & 0.47 & $(5.29)$ & 26.6 & (299) & 0.46 & $(5.19)$ & 26.5 & (298) & 1.03 & (11.6) & 44.9 & (505) & 1123 \\
\hline 11 & 0.35 & $(4.60)$ & 24.4 & $(322)$ & 0.36 & $(4.75)$ & 23.1 & (305) & 2.71 & $(35.8)$ & 49.1 & (648) & 1321 \\
\hline 12 & 1.06 & (14.5) & 22.2 & (304) & 1.02 & $(14.0)$ & 21 & (288) & 2.15 & $(29.5)$ & 52.6 & (721) & 1371 \\
\hline 13 & 0.34 & $(5.03)$ & 20.5 & $(300)$ & 0.3 & $(4.40)$ & 21.1 & (310) & 1.31 & $(19.2)$ & 56.4 & (827) & 1466 \\
\hline 14 & 0.32 & $(4.62)$ & 19.3 & (283) & 0.31 & $(4.47)$ & 20.6 & (301) & 0.73 & $(10.7)$ & 58.7 & (858) & 1461 \\
\hline 15 & 0.29 & $(4.46)$ & 18.5 & $(281)$ & 0.3 & $(4.50)$ & 19.3 & (294) & 0.7 & $(10.7)$ & 60.9 & (928) & 1523 \\
\hline
\end{tabular}

${ }^{a} P_{i}$ and $P_{o}$ refer to inorganic and organic components respectively.

${ }^{b}$ Total $P$ values were obtained from the sum of the of bicarbonate, $\mathrm{NaOH}, \mathrm{HCl}$ and residual P fractions.

that a proportion of the amorphous Al component is complexed with organic matter. This has important implications with respect to P-sorption processes given the greater reactivity of organic Al compared to mineral-bound fractions (Bertsch and Bloom, 1996). This, however, requires further investigation.

\section{Phosphorus fractionation}

Total P concentrations ranged from 1149 to $1727 \mathrm{mg} \cdot \mathrm{kg}^{-1}$ (Table 4), which is within the typical range for WTR (300 to 4000 $\mathrm{mg} \cdot \mathrm{kg}^{-1}$; Dayton et al., 2003). These values are lower than total P concentrations reported for South African sewage sludges (range
4100 to $41000 \mathrm{mg} \cdot \mathrm{kg}^{-1}$; Korentajer, 1991)) and within the typical range for soils (200 to $5000 \mathrm{mg} \mathrm{P} \mathrm{kg}^{-1}$; Lindsay, 1979). The fractionation data (Table 4) suggests that most of the $\mathrm{P}$ is present in forms that are not readily available for plant uptake as the soluble inorganic $\mathrm{P}$ and the inorganic $\mathrm{P}$ held on mineral surfaces through weak chemical interactions only comprised a small fraction of total P (Table 4). Most of fractionated P was bound as organic, calcium and residual forms, for all WTR. The high concentration of P present in the fixed fractions for all WTR does, however, indicate that P-supplying capacity of these WTR is limited.

This has been demonstrated by Dayton and Basta (2001) who found that tomatoes grown on WTR exhibited P deficiency 
even when Olsen and Mehlich III extractable P values were within adequate soil levels. This suggests that WTR are unlikely to make a positive contribution to bioavailable P pools unless unavailable $\mathrm{P}$ is released from the fixed fractions through exchange or dissolution mechanisms. The organically-bound $\mathrm{P}$ fraction $P$ ranged from 24.6 to $54.7 \%$ and, though not considered immediately plant-available, mineralisation of this fraction may increase bioavailable inorganic $\mathrm{P}$ pools. The rate at which these organic compounds release $\mathrm{P}$ will be affected by the stability of the organic compounds, which may include both organic compounds derived from the raw water and from treatment chemicals (organic polymers, activated charcoal). Butkus et al. (1998) hypothesised that organic polymers, in addition to $\mathrm{Fe}$ and $\mathrm{Al}$ oxides, were responsible for a significant fraction of the P sorbed to a ferric WTR, where models predicted that phosphate associated with quaternary polyamine constituted up to $40 \%$ of the phosphate bound by the WTR at high P loadings. This finding is likely to apply equally to P present in the raw water when it comes into contact with the organic polymers used to treat the raw water. The poor correlation between the sum of organic $\mathrm{P}$ fractions (extracted with bicarbonate and hydroxide) and OC ( $r=-0.11)$ (Table 3$)$ suggests that $\mathrm{P}$ is not necessarily associated with the readily oxidisable organic carbon compounds in the WTR. As the method used to estimate OC in this study (dichromate oxidation) was developed for readily oxidisable carbon fractions it may not give a true reflection of recalcitrant carbon compounds. Given that $\mathrm{P}_{\mathrm{o}}$ was determined as the difference between total $\mathrm{P}$ and $\mathrm{P}_{\mathrm{i}}$, and that total $\mathrm{P}$ was determined on each extract after acid digestion, it is likely that the values determined for $\mathrm{P}_{\mathrm{o}}$ reflected $\mathrm{P}$ contained in the stable, recalcitrant carbon fractions of the WTR.

With the exception of WTR 5, the quantity of P present in non-labile $\mathrm{Ca}$ forms was low relative to other fractions (Table 4). Possibly, extensive precipitation of P-rich solid phases is inhibited by competing adsorption reactions (Dayton, 1995) and inherently low $\mathrm{P}$ contents. The positive correlation between $\mathrm{HCl}$ extractable $\mathrm{P}$ and $\mathrm{Ca}$ content $(r=0.76)$ (Table 3$)$ does, however, suggest an association between $\mathrm{P}$ and $\mathrm{Ca}$, although the mechanism of retention remains unclear. The labile $\mathrm{P}$ fractions (bicarbonate and hydroxide extracts) tended to increase with an increase in $\mathrm{Ca}$ content even though it is expected that $\mathrm{P}$ concentrations would decrease with an increase in Ca content due to solid-phase precipitation. Possibly, a proportion of inherent labile $\mathrm{P}$ is retained on $\mathrm{Ca}$ mineral surfaces through weak forces of attraction as opposed to surface precipitation or specific sorption processes.

Residual P ranged from 41.9 to $60.9 \%$ of the total (Table 4), and represented the largest fraction of the inherent $P$ in most of the residues. This fraction is expected to be comprised of inorganic and organic P strongly chemisorbed to mineral surfaces or occluded within mineral structures, and is considered 'fixed' and not available for plant uptake. The P sorbed to amorphous $\mathrm{Al}$ and $\mathrm{Fe}$ oxides (19.4 to $93.8 \mathrm{mg} \cdot \mathrm{kg}^{-1}$ ) (Table 4) reflects the addition of varying quantities of $\mathrm{Al}$ and Fe coagulants during the different treatment processes. The $\mathrm{P}$ sorbed to these oxide fractions comprises a significant fraction of total inherent P. It is difficult to determine from which fraction the oxalate extractable constituent is drawn without knowledge of amorphous $\mathrm{Al}$ and $\mathrm{Fe}$ distribution, although most oxalate $\mathrm{P}$ is expected to be extracted from the residual fraction. In addition, the formation of $\mathrm{Ca}$-oxalate salts during extraction may also reduce the effectiveness of the extractant in WTR containing appreciable amounts of available $\mathrm{Ca}$ (e.g. Maguire et al., 2001).

\section{Conclusions}

The characterisation of these 15 WTR has shown a high degree of variability in the chemical properties relevant to P-sorption and desorption processes. The use of specific treatment chemicals in varying quantities to treat raw water sources, which have their own distinctive characteristics, means that each residue has unique chemical properties. Phosphorus sorption processes should, therefore, be residue specific. The extent to which $\mathrm{P}$ is retained or released by WTR will nonetheless be extensively influenced by a few important composition variables. Amorphous $\mathrm{Al}$ and $\mathrm{Fe}$ oxide in particular, have been shown to be strongly correlated to P-sorption capacity (Dayton, 1995; Haustein et al., 2000; Yang et al., 2006), while high Ca contents favour the precipitation of insoluble calcium phosphates (Dayton, 1995). Phosphorus saturation indices have also been shown to give a good indication of P-fixing potential, particularly in Al- and Fe-based residues (Elliot et al., 2002, Ippolito et al., 2011). It follows, therefore, based on chemical characterisation data, that all residues would be expected to adsorb high amounts of P. Furthermore, elevated amorphous $\mathrm{Al}$ and $\mathrm{Fe}$ and Ca contents suggest that sorbed phosphorus will be retained in forms unavailable for plant uptake.

Chemical fractionation revealed that most of the $\mathrm{P}$ in the WTR was present in forms that were not available for plant uptake. While total P values were comparable to typical soils, most $\mathrm{P}$ was bound in non-labile organic or residual forms. This, in conjunction with their elevated quantities of reactive $\mathrm{Al}$ and $\mathrm{Fe}$ oxides, suggests that plants growing on WTR-amended soils may be subjected to growth-inhibiting P deficiency. While this has been confirmed by numerous studies involving pot experiments (Bugbee and Frink, 1985; Cox et al., 1997; Hyde and Morris, 2000), studies by Elliott et al. (1990), Basta (2000) and Hughes et al. (2005), have shown that under field conditions P deficiencies are not observed. For instance, Hughes et al. (2005) noted that ryegrass grown on WTR-amended soil showed no indication of $\mathrm{P}$ deficiency even though the grass roots were concentrated within a WTR mulch layer. This suggests that this residue has sufficient $\mathrm{P}$ to satisfy plant growth requirements even though labile $\mathrm{P}$ fractions were below adequate soil levels. The high amount of $\mathrm{P}$ present in organically-bound forms is, in this regard, of particular interest. The absence of $\mathrm{P}$ deficiencies under field conditions could be attributed to the slow mineralisation of this fraction. In addition to this, plants may themselves increase labile $\mathrm{P}$ pools through disequilibria and ligand desorption mechanisms.

However, despite results from work by Hughes et al. (2005) and others suggesting no negative impact under field conditions, variation in inherent $\mathrm{P}$ distribution means that agronomic applications of WTR should be treated independently. For example, research by Oladeji et al. (2007 and 2008) indicates that in P-deficient Florida soils additional P-sources are required to counter the high P-soprtion potential of the WTR used. With respect to the WTR investigated in this study, the content and availability of inherent $\mathrm{P}$ are thus also a consideration prior to land application. Residues with low amounts of labile P may, for example, require $P$ treatment prior to or at the time of land application. Ultimately, the success of land application needs to be assessed for each residue on a field scale. From an environmental perspective, the stability of the inherent $\mathrm{P}$ component is highly favourable and suggests that land application will not be negatively impacted by the excess surface runoff or leaching of P. In addition to this, the high P-sorption potential (low PSI values and elevated Ca content) of the WTR makes them suitable for use as eutrophication preventatives or ameliorants. 
Additional sorption studies will be required to assess the validity of this for these WTR.

\section{Acknowledgements}

We thank Elise Herselmann for organising and collection of the WTR used in this study and Tad Dorasamy for some of the basic analyses conducted. We also would like to thank the anonymous reviewers for their valuable comments and suggestions.

\section{References}

ALBRECHT AE (1972) Disposal of alum sludges. J. Am. Water Works Assoc. 64 46-52.

BABATUNDE AO and ZHAO YQ (2007) Constructive approaches toward water treatment works sludge management: an international review of beneficial reuses. Crit. Rev. Environ. Sci. Technol. 37 129-164.

BABATUNDE AO, ZHAO YQ, YANG Y and KEARNEY P (2008) Reuse of dewatered aluminium-coagulated water treatment residual to immobilize phosphorus: Batch and column using a condensed phosphate. Chem. Eng. J. 136 108-115.

BABATUNDE AO and ZHAO YQ (2009) Phosphorus removal in laboratory-scale unvegetated vertical subsurface flow constructed wetland systems using alum sludge as main substrate. Water Sci. Technol. 60 (2) 483-489.

BABATUNDE AO and ZHAO YQ (2010) Equilibrium and kinetic analysis of phosphorus adsorption from aqueous solution using waste alum sludge. J. Hazardous Mater. 184 746-752.

BASTA NT (2000) Examples and case studies of beneficial reuse of municipal by-products. In: Power JF and Dick WA (eds.) Land Application of Agricultural, Industrial and Municipal By-products. Book Series 6. Soil Science Society of America, Madison. 493-503.

BERTSCH PM and BLOOM PR (1996) Aluminium. In: Sparks DL (ed.) Methods of Soil Analysis, Part 3. Chemical Methods. Book Series no. 5. Soil Science Society of America, Madison. 526-527.

BOISVERTJ-P, TO TC, BERRAK A and JOLICOEUR C (1997) Phosphate adsorption in flocculation processes of aluminium sulphate and poly aluminium-silicate-sulphate. Water Res. 31 (8) 1939-1946.

BUGBEE GJ and FRINK CR (1985) Alum sludge as a soil amendment: effects on soil properties and plant growth. Connecticut Agric. Exp. Station Bull. 823. Connecticut Agric. Exp. Station, New Haven

BUTKUS MA, GRASSO D, SCHULTHESS CP and WIJNJA H (1998) Surface complexation modelling of phosphate adsorption by water treatment residual. J. Environ. Qual. 27 1055-1063.

COX AE, CAMBERATO JJ and SMITH BR (1997) Phosphate availability and inorganic transformation in an alum sludge-affected soil. J. Environ. Qual. 26 1393-1398.

DAYTON EA (1995) Beneficial use of drinking water treatment residuals. MSc Thesis, Oklahoma Agricultural and Mechanical Board of Regents, Oklahoma State University. Available online at http:// dc.library.okstate.edu/cdm/singleitem/collection/theses/id/678/ $\underline{\mathrm{rec} / 18}$ (verified September 2012).

DAYTON EA and BASTA NT (2001) Characterization of drinking water treatment residuals for use as a soil substitute. Water Environ. Res. 73 52-59.

DAYTON EA, BASTA NT, JAKOBER CA and HATTEY JA (2003) Using water treatment residuals to reduce phosphorus in agricultural runoff. J. Am. Water Works Assoc. 95 151-158.

DAYTON EA and BASTA NT (2005) A method for determining the phosphorus sorption capacity and amorphous aluminum of aluminum-based water treatment residuals. J. Environ. Qual. $\mathbf{3 4}$ $1112-1118$

ELLIOTT HA, DEMPSEY BA, HAMILTON DW and DEWOLFE JR (1990) Land application of water treatment sludges: Impacts and management. American Water Works Association Research Foundation, Denver, CO.

ELLIOTT HA, O'CONNOR GA, LU P and BRINTON S (2002) Influence of water treatment residuals on phosphorus solubility and leaching. J. Environ. Qual. 31 1362-1369.

HAUSTEIN GK, DANIEL TC, MILLER DM, MOORE PA Jr. and MCNEW RW (2000) Aluminium-containing residuals influence high-phosphorus soils and runoff water quality. J. Environ. Qual. 29 1954-1959.

HUGHES JC, TITSHALL LW, BUYEYE M, JOHNSTON MA, MOODLEY M and PECKU S (2005) Effects of land application of water treatment residue. WRC Report No. 1148/1/04. Water Research Commission, Pretoria.

IPPOLITO JA, BARBARICK KA, HEIL DM, CHANDLER JP and REDENTE EF (2003) Phosphorus retention mechanisms of a water treatment residual. J. Environ. Qual. 32 1857-1864.

IPPOLITO JA, BARBARICK KA and ELLIOTT HA (2011) Drinking water treatment residuals: A review of recent uses. J. Environ. Qual. $401-12$.

HYDE JE and MORRIS TF (2000) Phosphorus availability in soils amended with dewatered water treatment residual and metal concentrations with time in residual. J. Environ. Qual. 29 1896-1904.

KORENTAJER L (1991) A review of the agricultural use of sewage sludge: Benefits and potential hazards. Water SA 17 189-196.

LINDSAY WL (1979) Chemical Equilibria in Soils. John Wiley and Sons, New York.

LOEPPERT RH and INSKEEP WP (1996) Iron. In: Sparks DL (ed.) Methods of Soil Analysis, Part 3. Chemical Methods. Book Series no. 5. Soil Science Society of America, Madison. 648-650.

MAGUIRE RO, SIMS JT, DENTEL SK, COALE FJ and MAH JT (2001) Relationships between biosolids treatment process and soil phosphorus availability. J. Environ. Qual. 30 (3) 1023-1033.

MAKRIS KC, HARRIS WG, O'CONNOR GA, OBREZA TA and ELLIOTT HA (2005) Physicochemical properties related to longterm phosphorus retention by drinking water treatment residuals. Environ. Sci. Technol. 39 (11) 4280-4289.

MEHRA OP and JACKSON MN (1960) Iron oxide removal from soils and clays by dithionate-citrate system buffered with sodium bicarbonate. $7^{\text {th }}$ National Conference for Clays and Clay Minerals 317-327.

McKEAGUE JA (1967) An evaluation of 0.1 M pyrophosphate and pyrophosphate-dithionate in comparison with oxalate as extractants of the accumulation products in Podzols and some other soils. Can. J. Soil Sci. 47 95-99.

MURPHY J and RILEY HP (1962) A modified single solution method for the determination of phosphate in natural waters. In: Sparks DL (ed.). Methods of Soil Analysis, Part 3. Chemical Methods. Book Series no. 5. Soil Science Society of America, Madison. 908-909.

OLADEJI OO, O'CONNOR GA and BRINTON SR (2008) Surface applied water treatment residuals affect bioavailable phosphorus losses in Florida sands. J. Environ. Manage. 88 1593-1600.

OLADEJI OO, O'CONNOR GA, SARTAIN JB and NAIR VD (2007) Controlled application rate of water treatment residual for agronomic and environmental benefits. J. Environ. Qual. 36 1715-1724.

RAZALI M, ZHAO YQ and BRUEN M (2007) Effectiveness of a drinking-water treatment sludge in removing different phosphorus species from aqueous solution. Sep. Purif. Technol. 55 300-306.

SCHMIDT CJJ, ADRIAANSE FG and DU PREEZ CC (2004) Relationships between Ambic1 and Bray 1 extractable phosphorus in some South African arable soils. S. Afr. J. Plant Soil. 21(2) 71-79.

TITSHALL LW and HUGHES JC (2005) Characterisation of some South Africa water treatment residues and implications for land application. Water SA 31 299-307.

THE NON-AFFILIATED SOIL ANALYSIS WORK COMMITTEE (1990) Handbook of Standard Soil Testing Methods for Advisory Purposes. Soil Science Society of South Africa, Pretoria.

WALKLEY A (1947) A critical examination of a rapid method for determining organic carbon in soils: effect of variations in digestion conditions and of organic soil constituents. Soil Sci. 63 251-263.

YANG Y, ZHAO YQ, BABATUNDE AO, WANG L, REN YX and HAN Y (2006) Characteristics and mechanisms of phosphate adsorption on dewatered alum sludge. Sep. Purif. Technol. 51 193-200.

ZHANG TQ and MACKENZIE AF (1997) Changes of soil phosphorus fractions under long-term corn monoculture. Soil Sci. Soc. Am. J. $61485-493$ 